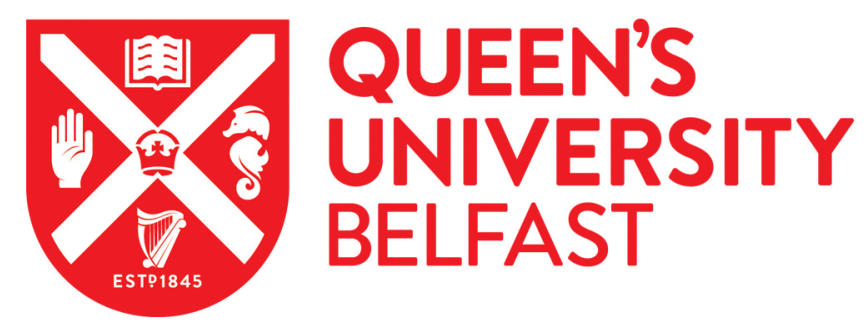

\title{
Selective monoalkylation of p-tert-butylcalix-[4]-arene in a methyl carbonate ionic liquid
}

Whiteside, R. E., Gunaratne, H. Q. N., Muzio, A. F. V., \& Nockemann, P. (2018). Selective monoalkylation of ptert-butylcalix-[4]-arene in a methyl carbonate ionic liquid. Chemical Communications.

https://doi.org/10.1039/c8cc05566a

Published in:

Chemical Communications

Document Version:

Peer reviewed version

Queen's University Belfast - Research Portal:

Link to publication record in Queen's University Belfast Research Portal

Publisher rights

(c) 2018 The Royal Society of Chemistry. This work is made available online in accordance with the publisher's policies. Please refer to any applicable terms of use of the publisher.

\section{General rights}

Copyright for the publications made accessible via the Queen's University Belfast Research Portal is retained by the author(s) and / or other copyright owners and it is a condition of accessing these publications that users recognise and abide by the legal requirements associated with these rights.

Take down policy

The Research Portal is Queen's institutional repository that provides access to Queen's research output. Every effort has been made to ensure that content in the Research Portal does not infringe any person's rights, or applicable UK laws. If you discover content in the Research Portal that you believe breaches copyright or violates any law, please contact openaccess@qub.ac.uk. 


\title{
Chemical Communications
}

\section{Selective Monoalkylation of $p$-tert-butylcalix-[4]-arene in a Methyl Carbonate Ionic Liquid}

++Received 00th January 20xx, Accepted 00th January 20xx

\author{
R. E. Whiteside", H. Q. Nimal Gunaratne, A. F. V. Muzio and P. Nockemann*
}

DOI: $10.1039 / \times 0 \times x 00000 x$

www.rsc.org/

\begin{abstract}
Methyl carbonate ionic liquids are shown to readily mono-deprotonate $p$-tert-butylcalix-[4]-arenes initiating the formation of an organic mono-anionic p-tert-butylcalix-[4]-arate salt, methanol and carbon dioxide. These calix-[4]-arate salts have been successfully used in alkylation reactions with dialkyl sulfates and alkyl halides to form a mono-alkylated single product with high yield. This method avoids the common use of alkali metal bases such as caesium fluoride hence providing a safer and more selective synthetic route.
\end{abstract}

p-tert-butylcalix-[4]-arene, TBC, is often described as a molecular basket; the tetrameric cyclic structure affords a cone shaped motif. Synthesised by Zinke and Ziegler in 1948 via a series of condensation steps involving $p$-tert-butylphenol and formaldehyde; they were often referred as insoluble, high melting solids. ${ }^{1}$ Since the synthesis of the basic calixarene motif there has been a huge interest in the solubility and functionalisation of these molecular baskets. ${ }^{2}$ There are two evident aspects to this functionalisation; the first being enhancement of solubility via the attachment of a somewhat polar species to either the lower or upper rim utilising a variety of organic reactions including esterification, sulfonation and Claisen rearrangements to name but a few. ${ }^{3}$ The second aspect of functionalisation focuses on the utilisation of the calixarene via the addition of a ligated species to assist in application to separations, host-guest complexes in many aspects of chemistry and biochemistry; including enhancement of rare earth luminescence. ${ }^{4}$

The monoethers of $p$-tert-butylcalix-[4]-arene are regularly used as starting materials for multi-functionalised calix-[4]arene host-molecules that requires functionalisation of a single $\mathrm{OH}$ group. Current methods of mono-alkylation primarily involve the use of a strong inorganic base such as $\mathrm{Na}[\mathrm{OMe}$, $\mathrm{K}[\mathrm{OAc}], \mathrm{NaH}, \mathrm{Cs}\left[\mathrm{CO}_{3}\right]$ or $\mathrm{CsF}$, which in each case carry their own issues regarding safety, solubility and the extent of deprotonation. ${ }^{5}$ The solubility of the starting material (TBC) itself also determines the sluggishness of reactions where,

a. QUILL Research Centre, School of Chemistry and Chemical Engineering, Queen's University of Belfast, Stranmillis Road, Belfast, Northern Ireland BT9 5AG, United Kingdom. E-mail: rwhiteside05@qub.ac.uk; p.nockemann@qub.ac.uk

Electronic Supplementary Information (ESI) available: [details of any supplementary information available should be included here]. See DOI: $10.1039 / x 0 \times x 00000 x$

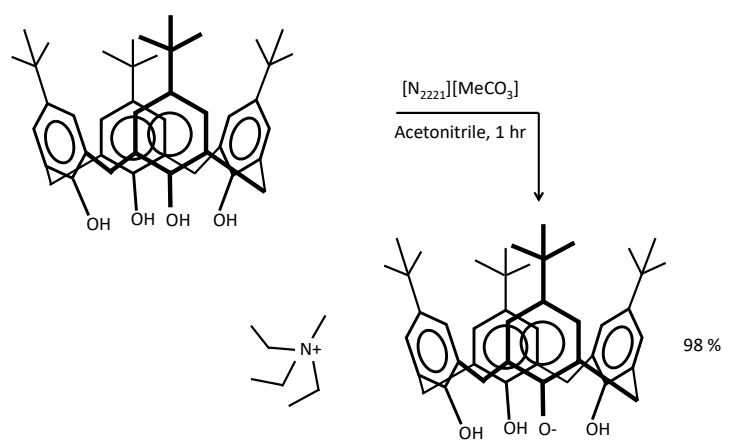

Figure 1. Synthesis of [ $\left.\mathrm{N}_{2221}\right][\mathrm{TBC}]$ using methyl carbonate ionic liquids

utilisation of weaker bases afford a greater mix of di-, tri- and tetra-ethers hence requiring elaborate separation techniques. Peculiarly, $\mathrm{Na}[\mathrm{OMe}]$ in acetonitrile has been shown to be an effective method of monoalkylation producing a yield of approximately $75 \%$ demonstrated by Shu et al. which contravenes the idea that use of stronger bases should result in a greater proportion of multiple alkylations. ${ }^{5 \mathrm{~b}}$ This further alkylation is believed to be due to the disruption of the stabilisation mechanism that would secure the distal proton that is often responsible for the $\mathrm{pK}_{\mathrm{a} 2}$ of the TBC starting material. Conventionally, the initial deprotonation results in a phenolic anion; this anion then stabilises the 3 other phenolic protons via a circular bonding and stabilisation mechanism that causes a pseudo covalent-hydrogen bond to form. The alkylation that occurs post deprotonation disrupts this stabilisation mechanism thus 'resetting' the $\mathrm{pK}_{\mathrm{a}}$ 's of the phenolic groups to those similar to the TBC starting material hence $\mathrm{pK}_{\mathrm{a} 1} c a$. $\mathrm{pK}_{\mathrm{a} 2}$ allowing for even weak bases such as $\mathrm{K}_{2} \mathrm{CO}_{3}$ to result in polyalkylated products.

Recent methods have been entailed to improve the green credentials of the mono-alkylations with a main shift towards utilisation of microwave (MW) irradiation and sulfonate alkylating reagents. Use of $\mathrm{MW}$ irradiation has rapidly decreased reaction times; however, the production of disubstituted species is still prevalent. ${ }^{6}$ Sulfonates have also been utilised along with a silyl triether derivative with use of pendant phenolic groups for mono-alkylation that, although effective, require elaborate synthesis and poor atom efficiency. ${ }^{7}$ 
In this work, we describe a simple method to obtain monoetherated calix-[4]-arenes in which basic methyl carbonate ionic liquids are utilised to form mono-calix-[4]-arate salts. Methyl carbonate ionic liquids have been a somewhat new revelation within the ionic liquids field. ${ }^{8}$ The non-halogenated anion is very appealing in regards to the green impact and toxicity of it as a solvent, however, the intrinsic instability of the basic anion is often viewed as a hindrance. First synthesised by Janson et al., ${ }^{8}$ by methylating trialkylamines with dimethyl carbonate, 'an environmentally benign alkylating reagent', affording a fully organic ionic liquid (Equation 1).

$$
\left(\mathrm{CH}_{3}\right)_{2} \mathrm{CO}_{3}+\mathrm{NR}_{3} \rightarrow\left[\mathrm{N}\left(\mathrm{CH}_{3}\right) \mathrm{R}_{3}\right]\left[\mathrm{CO}_{3} \mathrm{CH}_{3}\right]
$$

This methodology is not limited to ammonium cations and has been commercialised by Proionic $\mathrm{GmbH}$ who have developed the Carbonate Based Ionic Liquid Synthesis (CBILS ${ }^{\circledR}$, Proionic $\mathrm{GmbH}$ ) which can form methyl carbonate anion ILs with multiple popular cations such as phosphonium and imidazolium cations. ${ }^{8}$ The methyl carbonate anion when in contact with a Bronsted acids such as $\mathrm{HX}(\mathrm{X}=\mathrm{Cl}, \mathrm{Br}, \mathrm{I})$ will accept the proton and decomposes to form the [cation][X] IL, carbon dioxide and methanol.

The determination the $\mathrm{pK}_{\mathrm{a}}$ of TBC and other calixarenes has been sought using a variety of methods including ammonium salts of p-nitrophenolate, 2,4-dinitrophenolate, and picrate, however a majority of these measurements have only been possible in organic molecular solvents due to the very poor solubility of calixarene compounds such as TBC in aqueous and polar solvents. ${ }^{9}$ The first $\mathrm{pK}_{\mathrm{a}}$ measurement of a simple calix[4]-arene was achieved by Böhmer, et al. by the addition of a nitro functionality to the upper rim to improve solubility. ${ }^{10} \mathrm{It}$ is plausible that the $\mathrm{pK}_{\mathrm{a}}$ 's of hydroxyl groups in TBC determines the manner in which mono-alkylation can be attained.

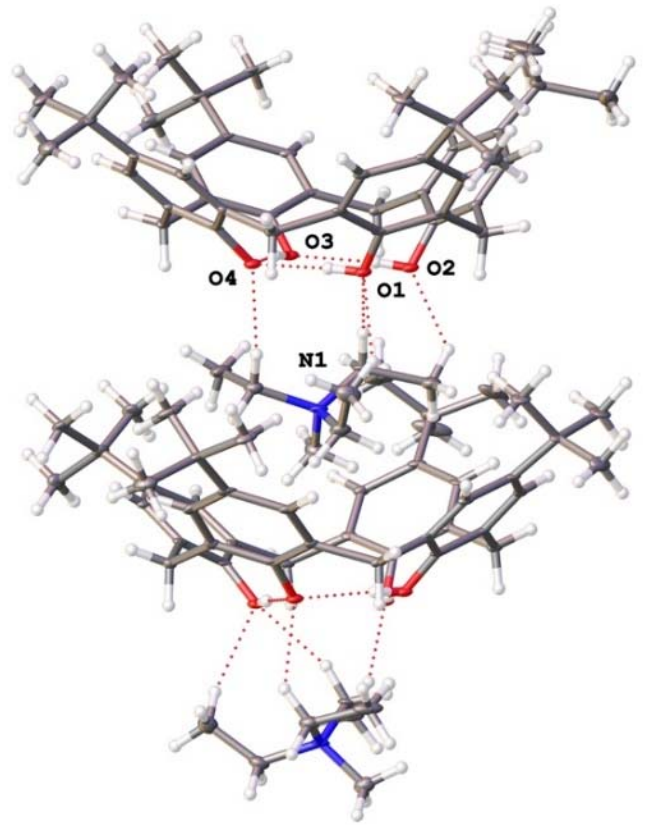

Figure 4. Single crystal diffraction determined structure of $\left[\mathrm{N}_{2221}\right][\mathrm{TBC}]$.

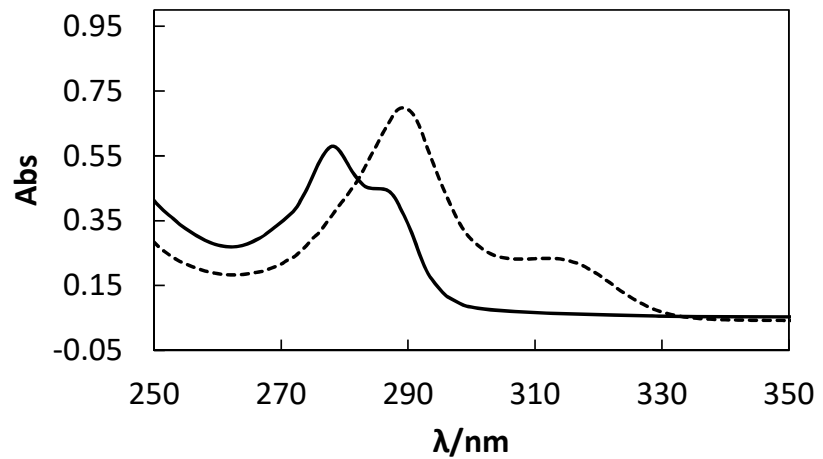

Figure 2. UV/Vis spectrum of [ $\left.\mathrm{N}_{2221}\right][\mathrm{TBC}]$ in MeCN (dashed) and with excess triflic acid added.(solid).

The higher basicity of the methyl carbonate anion compared to acetate is often noted; the addition of a Brønsted acid of an anion of choice (i.e. TBC), the methyl carbonate anion decomposes into $\mathrm{MeOH}$ and $\mathrm{CO}_{2}$ and the ionic salt with the conjugate base as the anion is obtained. ${ }^{11}$ The tert-butyl motif on the calix-[4]-arene has a significant effect on the dissociation constant of the phenolic proton; with $p$ methylcalix-[4]-arene and $p$-tert-butylcalix-[4]-arene having $\mathrm{pK}_{a} \mathrm{~S}$ of 6.0 and 4.3 respectively. This large change in $\mathrm{pK}_{\mathrm{a}}$ is believed to be due to subtle conformational effects due to the differing sizes of the alkyl substituents. ${ }^{2}$ This structural effect and the decrease in $\mathrm{pK}_{\mathrm{a}}$ allow for the acid base chemistry of the methyl carbonate anion to be utilised effectively as a new synthetic method.

As aforementioned, the stability of the basic anion is often viewed as a hindrance; however, in this work it is used seamlessly to provide a mono-deprotonation of $p$-tertbutylcalix-[4]-arene hence forming a calix-[4]-arate salt of an organic cation, cleanly in near quantitative yield, which in turn allows for a dramatically improved solubility and starting material for a mono-alkylations. This has been successful for a variety of cations including triethylmethylamine, [ $\left.N_{2} \begin{array}{llll}2 & 2 & 1\end{array}\right]$, and tributylmethylamine [ $\mathrm{N}_{4} 4_{4} 4_{1}$ ].

As shown in Figure 4. Single crystal diffraction determined

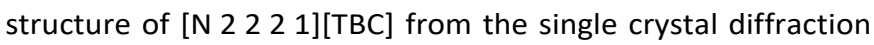
determined structure of $\left[N_{2221}\right][T B C]$ the single deprotonation causes a distortion in the cone conformer. The cation although hydrogen bonding dominantly occurs with the lower rim it is cradled by the upper rim. In the $\left[\mathrm{N}_{2221}\right]$ [TBC] structure, the majority of hydrogen bonding interactions occur between the lower rim of the TBC and the C-1 positions of the cation alkyl substituents. The $\left[\mathrm{N}_{2221}\right]$ cation is small and compact and was found to be cradled by the upper rim of the

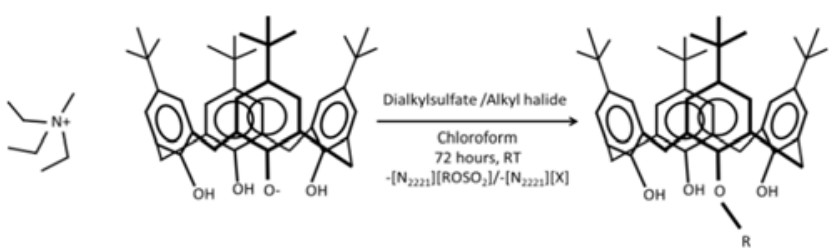

Figure 3. Reaction schematic for the alkylation of tert-butylcalix-4-arenes from organic salts. 
TBC with suspected $\pi$ interactions. The $\left[\mathrm{N}_{2221}\right]$ cation lies at its closest point $2.182 \AA$ from the lower rim and $2.812 \AA$ from the aromatic carbons of the upper rim / calixarene cavity. In the [ $\mathrm{N}_{4441}$ ] example (Supplementary) the cation cannot fit within the cavity instead it clusters around the lower rim of the deprotonated TBC in close proximity to another ion pair. Lying approximately $2.676 \AA$ at its closes point to the lower rim the interaction is comparable with the smaller $\left[\mathrm{N}_{2221}\right]$ cation.

Mono-deprotonation occurs exclusively as the $\mathrm{pK}_{\mathrm{a}} 1$ of the TBC in the cone conformer is significantly lower than the $\mathrm{pK}_{\mathrm{a}} 2$ of the deprotonated form. The $\mathrm{pK}_{\mathrm{a}} 2$ of the deprotonated TBC is estimated to be $c a 11$, which is not in the remit of the methyl carbonate anion (estimated to undergo the simultaneous protonation and decomposition in the presence of compounds with a $\mathrm{pK}_{\mathrm{a}}$ below 9). This is further supported by the enhanced cyclic hydrogen bonding of the deprotonated TBC motif.

Previous work by Woolfall and Cunningham utilised UV/Vis spectroscopy as a methodology to determine the $\mathrm{pK}_{\mathrm{a}}$ and mono deprotonation of TBC in acetonitrile. ${ }^{12}$ It was observed that with the addition of strong organic bases such as 1,8-Diazabicyclo[5.4.0] undec-7-ene, DBU to TBC in acetonitrile there is a spectral change that corresponds to the first deprotonation within the four phenolic groups. The change itself consists of a shift in $\lambda_{\max }$ and a shoulder appearing at 315 $\mathrm{nm}$, however, upon the addition of triflic acid the shift and shoulder formed is reversed.

This study was repeated with the p-tert-butylcalix-[4]-arate salts in acetonitrile and to these solutions varying amounts of DBU were added and spectra observed. A standard solution of the calix-[4]-arate salt was formed, the solution was diluted using acetonitrile and differing concentrations of the strong base DBU added. No changes in spectra were observed with increasing $[\mathrm{DBU}]$ indicating that the $T B C$ is already
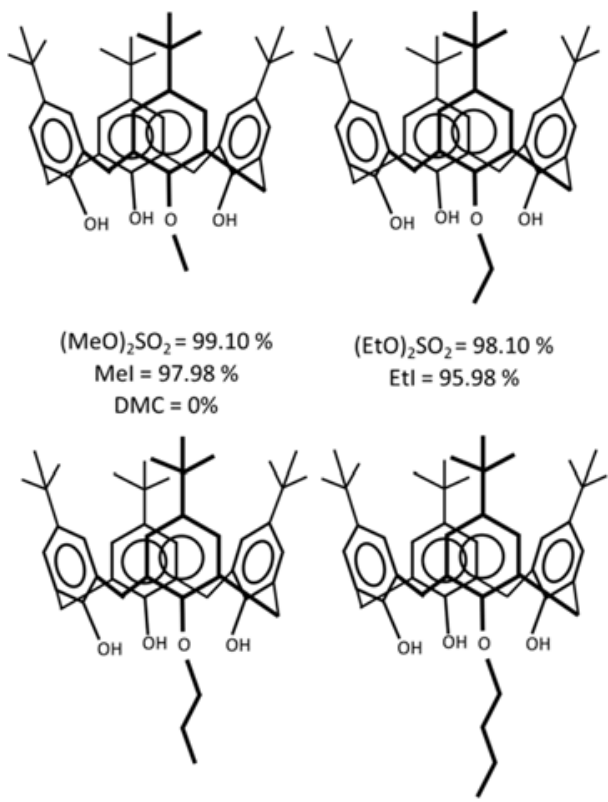

$(\mathrm{PrO}){ }_{2} \mathrm{SO}_{2}=70.76 \%$ $\mathrm{Prl}=75.90 \%$
$(\mathrm{BuO})_{2} \mathrm{SO}_{2}=70.20 \%$ $\mathrm{Bul}=75.20 \%$
Figure 5. Products obtained with yields for alkylations of $\left[\mathrm{N}_{2221}\right][\mathrm{TBC}]$ with dialkyl sulfates and alkyl halides. deprotonated. It should also be noted that the shape of the initial solutions is near identical to that reported for the TBC with 1 equiv. DBU as shown in Figure 2. The addition of triflic acid, however, showed a significant shift and loss of shoulder indicative of the formation of a neutral TBC species further confirming the deprotonation via the methyl carbonate anion.

This deprotonation is also critical in interrupting the 'circular hydrogen bonding' within the phenolic protons which, is known especially for its strength in tetramer calix's as described by Tobiason and Shinkai et $a .{ }^{12}$ The single deprotonation via the formation of this organic salt allows for a new opportunity for the single alkylation of TBC without the use of any bases. The removal of this base intrinsically prevents the formation of di-, tri- and tetra-alkylated species hence bypassing elaborate separation processes. The use of the organic salt also improves the solubility of the starting material allowing for reactions to be completed in concentrated solutions and under mild conditions. Further to this, the initial issues regarding preferential solubility of the ether products over the tert-butylcalix-[4]-arene stating material i.e. a further preventative measure towards multiple alkylations.

Mono-alkylations of [ $\left.\mathrm{N}_{2221}\right][\mathrm{TBC}]$ have been successfully carried out using both dialkyl sulfates and alkyl halides with good yield and minimal separation techniques. Using a standard procedure of dissolving [ $\left.\mathrm{N}_{2} 2_{2} 21\right][\mathrm{TBC}]$ in chloroform and 1.1 mole equiv of an alkylating agent, the solution is stirred at room temperature for 72 hours. Isolation simply requires washing with water and concentration under vacuum of the organic layer to afford an off white solid in every case. Specifically, with small chain alkylating agents the by-product salt is readily removed with water.

Achieving high yields within methylation and ethylation reactions, the decrease in yield as chain length increases is believed to be due to general lower reactivity. Current synthetic methods requiring mono-propylation or butylation require a top-down approach via the selective removal of ether groups from TBC to achieve comparable yields of 35$95 \%$, however, these often incorporate the use of tags and protecting groups. In comparison, from a bottom-up approach utilising a sodium salt via $\mathrm{Na}[\mathrm{OMe}]$, the highest yields are 47$75 \% .{ }^{5,13}$

In regards to the conformers achieved via this alkylation technique, it is believed that different conformers may dominate depending on the alkylating agent is used, however, multiple variations are present in each product, which is observed via subtle changes in the ${ }^{1} \mathrm{H} \mathrm{NMR}(\mathrm{SI})$, asymmetry within the TBC after alkylation is evident from ${ }^{1} \mathrm{H}$ NMR spectroscopy together with the utilisation of electron spray mass spectroscopy to eliminate any ambiguity regarding the presence of only mono-alkylated TBCs.

However, the presence of multiple conformers is expected as due to the aforementioned disruption in the circular phenolic hydrogen bonding due to mono-substitution. All conformers can exist in the mono-alkylated products. From ${ }^{1} \mathrm{H}$ NMR as a function of time we can see $100 \%$ conversion is achieved in all dialkyl sulphates and alkyl iodides. Studies with dimethyl 
carbonate, DMC, were carried out but found to be unsuccessful. The exclusive mono-alkylation of the TBC is controlled via the removal of base from the reaction mixture due to the utilisation of the mono-deprotonated calixarate salt. Within literature there are no reports of calixarene alkylations without the use of a base to initiate the reaction hence highlighting the significance of this new 'base-free' methodology.

In this work, we have demonstrated the facile synthesis of organic mono-calix-[4]-arate salts in near quantitative yields from methyl carbonate ionic liquids. These organic salts have been successfully applied to selective alkylation reactions with dialkyl sulfates and alkyl halides to form single mono-alkylated products with high yield. This method avoids the use of expensive alkali metal bases hence providing a safer and selective synthetic route that in future may also be successfully applied to further selective alkylations. The prevalence of the $p$-tert-butylcalixa-[4]-rene motif and the development of a simplistic and new starting point for functionalisation allows for new perspectives. In summary, this new synthetic route transforms a percieved weakness of methyl carbonate ionic liquids into a useful property. ${ }^{15}$ Omitting the need for expensive inorganic bases (i.e. ceasium carbonate) we have developed a controlled method of mono-alkylation without the need for strong bases which are often used in large excess.

\section{Conflicts of interest}

There are no conflicts to declare

\section{Notes and references}

‡ Triethylmethylammonium p-tert-butylcalix-[4]-arate, [ $\mathrm{N}_{\mathbf{2 2 2 1}}$ ][TBC]: Equimolar amounts of triethylmethylammonium methyl carbonate $(2.5 \mathrm{~g}, 13.07 \mathrm{mmol})$ and $p$-tert-butylcalix-4arene $(8.48 \mathrm{~g}, 13.07 \mathrm{mmol})$ were mixed together in acetonitrile $(75 \mathrm{~mL})$ and sonicated for 45 minutes until effervescence had ceased. The solution is concentrated under vacuum to form a white crystalline solid. (9.76 g, $12.88 \mathrm{mmol}, 98.0 \%$ )

Alkylation of p-tert-butylcalix-4-arene: To a concentrated solution of [cation][TBC] $(0.262 \mathrm{mmol})$ in chloroform $(2.5 \mathrm{~mL})$, dialkylsulfate/alkyl iodide $(0.288 \mathrm{mmol})$ and stirred $(72 \mathrm{hr}, \mathrm{RT})$. The reaction mixture is washed with water $(2 \times 2 \mathrm{~mL})$ and organic layer extracted. The residual chloroform is removed under vacuum affording and off white solid.

NMR spectra were recorded on a Bruker $600 \mathrm{MHz}$ or $400 \mathrm{MHz}$ spectrometer. UV/Vis spectra were measured using an Agilent Cary 350 spectrometer. Electrospray time of flight mass spectrometry (ESI-MS) was completed using a Waters LCT Premier spectrometer.

We thank C. McGrann (MS), D. Baskerville (MS), R. W. Murphy (NMR) and Analytical Services and Environmental Projects Division, ASEP. We thank K. Seddon and R. S. Kalb (Proionic $\mathrm{GmbH}$ ) for their valuable comments.

1 A. Zinke and S. Pucher, Monatshefte für Chemie/Chemical Monthly, 1948, 79, 26-41.

2 (a) C. D. Gutsche, Accounts of Chemical Research, 1983, 16, 161-170; (b) M. Strobel, K. Kita-Tokarczyk, A. Taubert, C.
Vebert, P. A. Heiney, M. Chami, and W. Meier, Adv. Funct. Mater., 2006, 16, 2, 252-259.

3 (a)S. Shinkai, K. Araki, T. Tsubaki, T. Arimura and O. Manabe, J. Chem. Soc. Perk. T1., 1987,1, 2297-2299; (b) S. Shinkai, S. Mori, T. Tsubaki, T. Sone and O. Manabe, Tet. Lett., 1984, 25, 5315-5318; (c) S. Shinkai, S. Mori, H. Koreishi, T. Tsubaki and O. Manabe, J. Am. Chem. Soc., 1986, 108, 2409-2416.(d) P. Jose and S. Menon, Bioinorg. Chem. Appl., 2007, 65815. (e) D. C. Gutsche,A. J. Levine, and P. K. Sujeeth, J. Org. Chem., 1985, 50, 5802-5806.

4 (a) N. Sabbatini, M. Guardigli, A. Mecati, V. Balzani, R. Ungaro, E. Ghidini, A. Casnati and A. Pochini, Chem. Comm., 1990, 878-879; (b) J. J. Rebek, Chem. Comm., 2000, 637-643. (c) D. A., Fulton, and J. F. Stoddart. Bioconjugate chemistry, 2001, 12, 655-672. (d) E. Mulugeta, Q. He, D. Sareen, S. J. Hong, J. H. OhV. M. Lynch, J. L. Sessler, S. K. Kim, and C. H. Lee, Chem., 2017, 3, 6, 1008-1020.

5 (a) O. A. Yesypenko, V. I. Boyko, M. A. Klyachina, S. V. Shishkina, O. V. Shishkin, V. V. Pyrozhenko, I. F. Tsymbal and V. I. Kalchenko, J. Incl. Phenom. Macrocycl. Chem., 2012, 74, 265-275; (b) C.-M. Shu, W.-S. Chung, S.-H. Wu, Z.-S. Ho, L.-G. Lin, J. Org. Chem., 1999, 64, 2673-2679; (c) F. SantoyoGonzález, A. Torres-Pinedo and A. Sanchéz-Ortega, J. org. chem, 2000, 65, 14, 4409-4414. (d) J. Bois, J. Espinas, U. Darbost, C. Felix, C. Duchamp, D. Bouchu, M. Taoufik, and I. Bonnamour, J. org. chem. 2010, 75, 22, 7550-7558. (e) F. Yang, H. Guo, and J. Vicens, 2014, J. Incl. Phenom. Macrocycl. Chem, 2014, 80, 3-4, 177-186. (f) L. C. Groenen, B. H. Ruël, A. Casnati, W. Verboom, A. Pochini, R. Ungaro, and D. N. Reinhoudt, Tetrahedron, 1991, 47, 39, 8379-8384.

6 (a) S. K. Nayak, M. K. Choudhary, Tet. Lett., 53 ,2012, 53, 141-144; (b) V.A. Burilov, R. I. Nugmanov, R. R. Ibragimova, S. E. Solovieva, I. S. Antipin, and A. I.Konovalov, Mendeleev. Commun, 2013, 23, 2, 113-115.

7 S. Shang, D. V. Khasnis, J. M. Burton, C. J. Santini, M. Fan, A. C. Small, and M. Lattman, Organometallics, 1994, 13, 51575159;

8 (a) J. D. Holbrey, W. M. Reichert, I. Tkatchenko, E. Bouajila, O. Walter, I. Tommasi and R. D. Rogers, Chem. Comm. 2003, 28-29; (b) B. Albert and M. Jansen, Z. Anorg. Allg. Chem 1995, 621, 1735-1740; (c) S. R. Labafzadeh, K. J. Helminen, I. Kilpeläinen, and A. W. T. King, ChemSusChem, 2015, 8, 1, 7781; (d) m. Fabris, V. Lucchini, M. Noè, A. Perosa, and M. Selva, Chem. Eur. J. ,2009, 15, 12273-12282 (d) R. S.Kalb, E. N. Stepurko, V. N. Emel'yanenko and S. P. Verevkin, Phys. Chem. Chem. Phys., 2018,18,46,31904-31913. (e) R. S. Kalb, W. Wesner, R. Hermann, M. Kotschan, M. Schelch and W. Staber, WO2005021484, EP1658262B1 and US8075803B2, 2005 (f) R. S. Kalb, WO2008052860 and EP2079705B1, 2008. (g); R. S. Kalb, WO2008052863 and EP2079707B1, 2008 (h) R. S. Kalb, WO 2008052861, 2008.

9 (a) A. Koji, I. Koji, S. Seiji and M. Tsutomu, Bull. Chem. Soc. Jpn , 1990, 63, 3480-3485; (b) S. Shinkai, K. Araki, P. D. Grootenhuis and D. N. Reinhoudt, J. Chem. Soc., Perkin Trans. 2, 1991,0, 1883-1886.

10 V. Böhmer, E. Schade and W. Vogt, Macromol. Rapid. Commun., 1984, 5, 221-224.

11 C. Maton, K. Van Hecke and C. V. Steven, New. J. Chem., 2015, 39, 461-468.

12 (a) I. D. Cunningham and M. Woolfall, J. Org. Chem., 2005, 70, 9248-9256; (b) S. Keller, G. Schuster and F. Tobiason, Polymeric Materials: Science and Engineering. 1987, 57, 906910.

13 Y. I. Matvieiev, V. I. Boyko, A. A. Podoprigorina and V. I. Kalchenko, J. Incl. Phenom. Macrocycl. Chem., 2008, 61, 89-92.

14 Kuzmina O, Hallett J, Application, Purification, and Recovery of Ionic Liquids, 2016, 82-85 Elsevier Inc. 